confidential environment dedicated to helping them continue in practice.

KrT HARLING, Dean, Faculty of Occupational Medicine, Royal College of Physicians, 6 St Andrew's Place, London NW1 4LB

\section{CPD and the Fellowship}

Sir: I have previously raised the issue of the Fellowship in these columns. CPD is also causing concern among members of the College. I would like to suggest linking these two processes. The Fellowship is currently a selfperpetuating oligarchy which cannot be justified on a democratic basis. I propose the following:

(1) Fellowship be awarded following the completion by a member of the College of two consecutive 3-year cycles of CPD.

(2) Fellows who fail to complete two 3-year cycles of CPD in any 9-year period should lose the Fellowship.

(3) Honorary Fellowships may continue to be awarded.

(4) Fellows who retire from active practice would continue to use the title of "FRCPsych (ret'd)".

This proposal would have the merit of linking Fellowship to an objective measure of one's commitment to continuing education and would also allow continued links with the College for members who are not practising primarily in psychiatry.

ADAM MOLIVER, Consultant Psychiatrist, East Gloucestershire NHS Trust, Charlton Lane, Cheltenham GL53 9DZ

\section{Incapacity Benefit}

Sir: I wonder if there are other colleagues whose patients have had substantial difficulties with the new Incapacity Benefit system. When it was first introduced in April 1995 I noticed little impact on my patients and was relieved that psychotic patients have generally been exempted from Benefit Agency Medical Service examinations. However, in 1996 I had a substantial number of out-patients with non-psychotic depressive illnesses taken off Incapacity Benefit by Benefits Agency Medical Service doctors (BAMS). In most cases this has caused them substantial distress and has led to a deterioration in their depressive condition.

In the majority of cases I have felt that suspension of benefit was not justified. Patients who have appealed have obtained copies of the Benefits Agency Medical Officers' report form as part of the appeal process and I would have had little difficulty, for most, in giving a substantially higher score than the Benefits Agency Doctor. I have accordingly written reports to support several of these appeals. I understand that 15 points are required to qualify for benefit on mental grounds, assessed by a special questionnaire for mental symptoms.

I wonder, therefore, if there has been a policy by the Benefits Agency to target this group and I feel that, if there is, the College should be active in making its protest felt on behalf of our patients. There is clearly no reason, other than saving money, to harass individuals in their 50 s who have taken early retirement on medical grounds and who have no realistic chance of working again. The aim seems simply to pressure them to stop claiming benefit altogether, which also I believe obliges them to pay a non-employed national insurance contribution until they reach pensionable age.

I would be most interested to hear if other psychiatrists have had similar experiences, as have several of my local colleagues, and if the College has any comments.

PHILIP D. MARShall, Consultant Psychiatrist, Cefn Coed Hospital, Cockett, Swansea SA2 OGH

\section{Postgraduate training and overseas experience}

Sir: I write this letter with the idea of bringing to light the general disadvantage that overseas trainees in psychiatry are faced with when compared with other specialities. Having had my basic training in India, I had to pass the PLAB (Professional and Linguistic Assessments Board, conducted by the GMC) examination as did a few of my colleagues in other specialities in order to undertake further training in this country.

However, 18 months down the line I find that my colleagues have successfully passed the MRCP or FRCS and are now either Specialist Registrars or at least eligible to apply for such a post. However, due to college requirements (Royal College of Psychiatrists, 1996) I have only just been deemed eliglble to sit the Part I, which I did in October 1996. I find myself faced with the prospect of working as a SHO for 2 years more, or one at the very least if the College decides to accept my overseas training. Given the fact that present Home Office regulations allow four years' permit free training, the best case scenario for me at the end of that period would be that I would have passed the MRCPsych II. On the other hand my colleagues may have been able to complete SpR training and be eligible for a CCST in their speciality.

I propose that overseas graduates be given the choice of sitting the Part $I$ in the first 6 months in 